\title{
Estudo observacional do comportamento empreendedor de Irineu Evangelista de Sousa da ótica de Filion no filme "Mauá - o Imperador e o Rei"
}

\author{
An observational study of the entrepreneurial behavior of Irineu Evangelista de Sousa from \\ the perspective of Filion in the film "Mauá - the Emperor and the King"
}

\author{
Fátima Regina Ney Matos ${ }^{1}$ \\ Waleska Vasconcelos Queiroz ${ }^{2}$ \\ Kátia Lene de Araújo Lopes ${ }^{3}$ \\ Gleildes dos Santos Lima Frota ${ }^{4}$ \\ Valdênia Maria Lima Leandro Saraiva ${ }^{5}$
}

\section{Resumo}

Análise do comportamento empreendedor de Irineu Evangelista de Sousa, observado no filme "Mauá - O Imperador e o Rei". Procurou-se usar como base argumentativa o trabalho de Louis Jacques Filion $(2004,2000,1993$, 1991) sobre características empreendedoras básicas - inovação, aprendizagem, rede de relações e visão. A escolha do tema deveu-se ao pouco conhecimento dos alunos de graduação e pós-graduação em administração - detectado em uma pesquisa exploratória informal - sobre os empreendedores brasileiros e seu papel na evolução econômica do país, sendo relevante este resgate histórico. Após cinco exibições coletivas e algumas exibições individuais do filme, foi realizado um estudo observacional, tipo de observação de "segunda mão", indireta e não participante, com produtivas discussões em equipe. Na revisão bibliográfica buscou-se contextualizar, de maneira sucinta, as características do comportamento empreendedor da ótica de Filion (1991). Pode-se concluir que as características empreendedoras propostas na tipologia do autor apresentam-se com vigor no comportamento do Barão de Mauá, um homem à frente de seu tempo e que procurou contribuir na construção de um novo projeto para o Brasil, possibilitando a transição de um modelo econômico agrário exportador e escravocrata para uma economia de mercado baseada na industrialização, no trabalho assalariado e na livre iniciativa, sendo esse conhecimento essencial para o desenvolvimento do senso crítico e analítico do aluno.

Palavras-chave: Empreendedorismo. Inovação. Aprendizagem. Rede de relações. Estudo observacional.

Artigo submetido em 08 de novembro de 2010 e aceito para publicação em 15 de setembro de 2011.

${ }^{1}$ Doutora em Administração pela Universidade Federal de Pernambuco; Professora adjunta da Universidade de Fortaleza. Endereço: UNIFOR,- Avenida Washington Soares, 1321, Bairro Edson Queiroz, CEP 60811-905, Fortaleza - CE, Brasil. E-mail fneymatos@globo.com

${ }^{2}$ Mestre em Administração pela Universidade Estadual do Ceará. Endereço: UECE - CMAAD - Avenida Paranjana, 1700, Campus do Itaperi, CEP 60740-000, Fortaleza - CE, Brasil. E-mail wvqueiroz@yahoo.com.br

${ }^{3}$ Mestre em Administração pela Universidade Estadual do Ceará; Coordenadora e Professora da Faculdade Lourenço Filho. Endereço: FTLF - Avenida Osório de Paiva, 395, Bairro: Parangaba, CEP 60720-000, Fortaleza - CE, Brasil. E-mail katialene@gmail.com

${ }^{4}$ Mestre em Administração pela Universidade Estadual do Ceará; Endereço: UECE - CMAAD - Avenida Paranjana, 1700, Campus do Itaperi, CEP 60740-000, Fortaleza - CE, Brasil. E-mail gleildeslima@hotmail.com

${ }^{5}$ Mestre em Administração pela Universidade Estadual do Ceará - Endereço: UECE - CMAAD - Avenida Paranjana, 1700, Campus do Itaperi, CEP 60740-000, Fortaleza - CE, Brasil. E-mail valdeniasaraiva@gmail.com 


\begin{abstract}
The objective of this study is to analyze the entrepreneur Irineu Evangelista de Sousa in the film "Maua - The Emperor and the King." We attempted to use as a basis of argument the study of Louis Jacques Filion (2004, 2000, 1999, 1993, 1991) on basic entrepreneurial characteristics - innovation, learning, network of relationships and vision. The choice of theme was due to poor knowledge of undergraduate and postgraduate studies in administration, observed in an informal exploratory study of Brazilian entrepreneurs and their role in the economic development of the country, which is an historical feat. After five collective viewings and some individual viewings of the film, an observational study was conducted, a type of "second hand" indirect and non-participative study, with productive team discussions. The literature review attempted to contextualize, briefly, the characteristics of entrepreneurial behavior from the perspective of Filion (1991). One may conclude that the entrepreneurial characteristics proposed in the typology of the author are presented vigorously concerning the behavior of the Baron of Maua, a man ahead of his time that sought to contribute to the construction of a new project in Brazil, enabling the transition from an agrarian economic model of exports and slavery to a market economy based on industrialization, wage labor and free enterprise. This knowledge is essential for the development of critical and analytical thinking of students, based on a teaching resource for easy assimilation.
\end{abstract}

Keywords: Entrepreneurship. Innovation. Learning. Network. Observational study.

\title{
Introdução
}

Como prática empírica, o empreendedorismo é tão antigo quanto o homem, embora, como conhecimento científico, seja um campo de estudo recente. A obra de Cantillon é o primeiro tratado sistemático em Economia que introduziu o termo "entrepreneur" - empreendedor - definido como o agente que compra meios de produção a certos preços, para poder combiná-los em um produto que irá vender a preços incertos (SCHUMPETER, 1968). Richard Cantillon, no século XVIII, propôs, em sua obra Ensaio sobre a natureza do comércio em geral uma ordem social e econômica baseada em três classes principais: proprietários fundiários, trabalhadores agrícolas e arrendatários capitalistas, mas reconheceu a importância dos trabalhadores manufatureiros, do artesão urbano independente, do comerciante e do artesão na construção civil (COUTINHO, 2005).

A utilização seminal do termo empreendedorismo é também atribuída a Jean Baptiste Say, que o teria utilizado por volta do ano 1800 para designar a transferência de recursos de áreas de baixa produtividade para outras com melhor produtividade e rendimento (VERBEU, WENNEKERS e THURIK, 2001). O empreendedor, no sentido atual do termo, surgiu na Inglaterra, com o advento da Revolução Industrial (SCHÖLLHAMMER e KURILOFF, 1979).

A definição de empreendedorismo geralmente envolve aspectos de criação de empresa, inovação, risco, aprendizagem e redes. Nesse sentido, os empreendedores são "[...] indivíduos que agem independentemente ou como parte de uma organização, que criam um novo empreendimento ou desenvolvem uma inovação e assumem riscos ao introduzi-la no mercado" (HITT, IRELAND e HOSKISSON, 2003, p. 529). Autores como Shane e Venkataraman (2000) e Filion (2004) relacionam o fenômeno empreendedor com fazer algo novo e diferente com o objetivo de gerar riqueza e agregar valor para a sociedade.

Baumol (1993) considera como característica dos empreendedores o uso da imaginação, a ousadia, a engenhosidade, a liderança, a persistência e a determinação. O empreendedor é "[...] alguém que se especializa em tomar decisões ponderadas sobre a alocação de recursos escassos” (CASSON, 1982, p. 151); é o indivíduo que "[...] cria um novo negócio em face do risco e da incerteza com a finalidade de lucro e crescimento pela identificação de oportunidades e pela reunião dos recursos necessários para capitalizá-lo" (SCARBOROUGH e ZIMMERER, 2000, p. 4). 
Empreendedores são indivíduos que conseguem mobilizar recursos, geralmente escassos no meio institucional, por meio da utilização de estratégias socioeconômicas, de cooptação de recursos estratégicos (influência, amizade, confiança, favores), cooptação de "bens públicos" (legitimidade, acesso à mídia, endossos, informação), cooptação de bens subutilizados (empréstimos e obtenção definitiva de materiais, equipamentos, instalações).

Drucker (1986, p. 15) considera o empreendedor um "tomador de decisões", enquanto McClelland (1991, p. 68) o identifica como um indivíduo "[...] fortemente motivado pela necessidade de realização, que não gosta de rotinas e nem de trabalho repetitivo".

Kao (1989) entende que empreendedorismo e criatividade são qualidades humanas atemporais e intimamente relacionadas, ao passo que o comportamento empreendedor envolve a habilidade de identificar oportunidades. Para Martinelli (1994), o empreendedor é um ator social que desempenha papéis fundamentais em instituições da economia de mercado, o que o leva a ocupar posições importantes na sociedade capitalista.

Souza (2005), na Tabela 1, apresentam uma matriz com as características empreendedoras propostas por diferentes autores.

Tabela 1

\section{Matriz de Características de Empreendedores}

\begin{tabular}{|c|c|c|c|c|c|c|c|c|c|c|c|c|c|c|c|c|c|}
\hline \multirow[b]{2}{*}{ Características } & \multicolumn{16}{|c|}{ Autores } & \\
\hline & 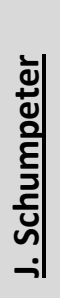 & $\begin{array}{l}\frac{0}{0} \\
\frac{\pi}{0} \\
\overline{0} \\
\frac{\pi}{0} \\
\sum \\
0 \\
0\end{array}$ & 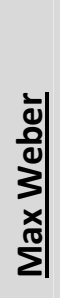 & 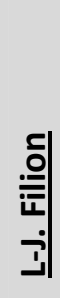 & 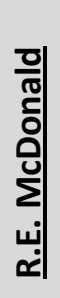 & 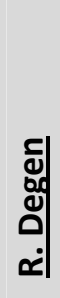 & 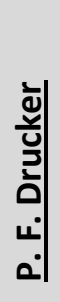 & 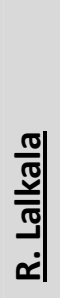 & 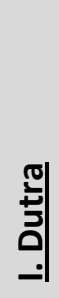 & 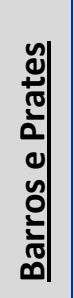 & 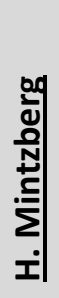 & 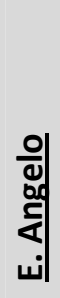 & 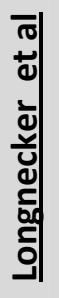 & | & 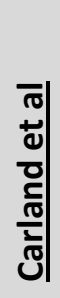 & 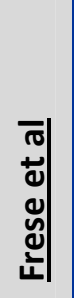 & 矛| \\
\hline $\begin{array}{l}\text { Busca de } \\
\text { oportunidades }\end{array}$ & $x$ & $x$ & & $\mathrm{x}$ & $x$ & $x$ & $x$ & & $x$ & & $x$ & $x$ & $x$ & $x$ & & & 11 \\
\hline $\begin{array}{l}\text { Conhecimento do } \\
\text { mercado }\end{array}$ & & & & & & $x$ & $x$ & $x$ & & & & $x$ & & $x$ & & & 5 \\
\hline $\begin{array}{l}\text { Conhecimento do } \\
\text { produto }\end{array}$ & & & & & & $x$ & $x$ & $x$ & & & & $x$ & & $x$ & & & 5 \\
\hline Correr riscos & $x$ & $x$ & & $x$ & $x$ & $x$ & $x$ & & & & $x$ & $x$ & & $x$ & $x$ & & 10 \\
\hline
\end{tabular}




\begin{tabular}{|c|c|c|c|c|c|c|c|c|c|c|c|c|c|c|c|c|c|}
\hline \multirow[b]{2}{*}{ Características } & \multicolumn{16}{|c|}{ Autores } & \\
\hline & 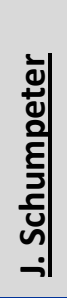 & 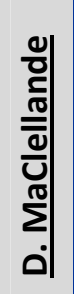 & 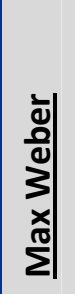 & 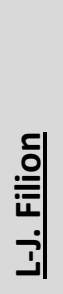 & 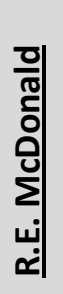 & 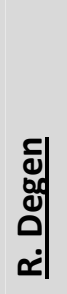 & 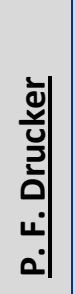 & $\begin{array}{l}\frac{\pi}{\pi} \\
\frac{a}{\pi} \\
a\end{array}$ & 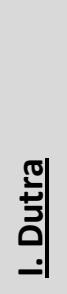 & 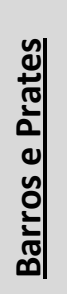 & 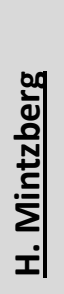 & 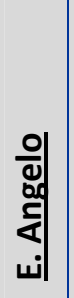 & 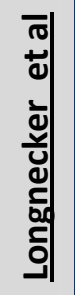 & : & 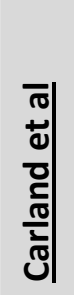 & 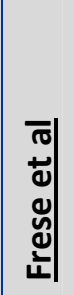 & 茕 \\
\hline Criatividade & & $x$ & & $x$ & & $x$ & & $x$ & $x$ & $x$ & & $x$ & & $x$ & $x$ & & 9 \\
\hline Iniciativa & $x$ & $x$ & & $x$ & & & & & $x$ & & & & & $x$ & & $x$ & 6 \\
\hline Inovação & $x$ & $x$ & $x$ & $x$ & $x$ & $x$ & $x$ & $x$ & $x$ & $x$ & $x$ & $x$ & $x$ & $x$ & $x$ & $x$ & 16 \\
\hline Liderança & $x$ & $x$ & $x$ & $x$ & $x$ & & $x$ & & & & $x$ & & & & & & 7 \\
\hline $\begin{array}{l}\text { Necessidade de } \\
\text { realização }\end{array}$ & $x$ & $x$ & & & & & & & & & $X$ & & & & $x$ & $x$ & 5 \\
\hline Proatividade & $x$ & $x$ & & $x$ & & & & & & & & & & & $x$ & $x$ & 5 \\
\hline Visionaridade & & & & $x$ & & & & & $x$ & & $x$ & & & $x$ & & $x$ & 5 \\
\hline
\end{tabular}

Fonte: Souza, 2005, p. 17.

Estudos mais recentes, realizados na Grécia por Apospori, Papalexandris e Galanaki (2005) com o intuído de apontar similaridades entre o perfil motivacional de empreendedores e executivos, com base na tipologia de McClelland (1991), identificaram que realização, motivação e responsabilidade são os fatores mais significativos encontrados no perfil dos dois grupos. Empreendedores apresentam maior motivação que os administradores (STEWART JR. e ROTH, 2007) e mais comprometimento emocional com o negócio (TANG, 2008). Taormina e Lao (2007) mostraram que, na China, as características psicológicas exercem forte influência sobre empreendedores potenciais e que o ambiente de negócios influencia os empreendedores de sucesso.

Como é possível observar, não existe ainda um conceito definitivo que englobe todos os aspectos do fenômeno empreendedor, padronize características ou possibilite a construção de uma teoria no tema (VERSTRAETE, 2001). Sem tirar o crédito dos demais autores que apontaram características dos empreendedores, optou-se por utilizar neste artigo a tipologia proposta por Filion (2004, 2000, 1999, 1993, 1991), por ser ao mesmo tempo, sucinta e abranger as demais características propostas. 
Assim, o objetivo neste trabalho foi analisar as características empreendedoras de Irineu Evangelista de Souza observadas no filme "Mauá - O Imperador e o Rei". Procurou-se usar como base argumentativa o trabalho de Louis Jacques Filion $(2004,2000$, 1999, 1993, 1991) sobre características empreendedoras básicas - inovação, aprendizagem, rede de relações e visão. O Barão de Mauá já foi "visitado" por Bertero e Iwai (2005), que procuraram identificar suas estratégias de negócios. Concluíram que, de uma perspectiva estratégica, não causa surpresa o insucesso de Mauá a partir de 1877.

O filme analisado é um recorte da história do Brasil imperial e baseia-se em dados secundários. A motivação para a escolha do tema deve-se à crescente aceitação e utilização pela comunidade acadêmica do estudo observacional como recurso didático e eficiente instrumento de ensino e pesquisa em administração.

\section{O Empreendedorismo da Ótica de Filion}

O marco referencial deste artigo são os estudos de Filion $(2004,2000,1999,1993,1991)$, que define o empreendedorismo como "[...] o processo pelo qual se faz algo novo (algo criativo) e algo diferente (algo inovador) com a finalidade de gerar riqueza para indivíduos e agregar valor para a sociedade" e o empreendedor "[...] como uma pessoa que imagina, desenvolve e realiza visões" (FILION, 2004, p. 65) e que apresenta quatro características básicas: aprendizagem, rede de relações, visão e inovação.

\section{Aprendizagem}

De acordo com Marshall (1985), o conhecimento é o motor mais poderoso da produção, "um recurso econômico básico" que deverá permear todas as organizações, possibilitando, ao longo do século XXI, a formação de uma "sociedade do conhecimento" (DRUCKER, 1994).

Lundvall (1992) aponta quatro tipos de conhecimento empregados nos processos de aprendizagem: conhecimento sobre os fatos (know-what); conhecimento científico (know-why); conhecimento proveniente das competências práticas acumuladas (know-how) e conhecimento relacionado "a capacidade social de quem sabe fazer o que" (know-who). Este último tipo de conhecimento engloba a construção de relações sociais nas quais especialistas permitem o acesso e o uso de seus conhecimentos de maneira eficiente. Assim, o processo de aprendizagem é potencializado pela dimensão social e interorganizativa das trocas entre estes diferentes tipos de conhecimento (CORÒ, 1999).

De acordo com Hamel e Prahalad (1995, p. 71), [...] o que impede as empresas de criar um futuro é uma base instalada de ideias - as convenções inquestionáveis, a visão míope das oportunidades e ameaças e os precedentes não desafiados que constituem a estrutura gerencial existente", ou seja, são os "modelos mentais" introjetados. Os modelos mentais são definidos por Senge (1990, p. 201) como "[...] imagens internas profundamente arraigadas sobre o funcionamento do mundo, imagens que nos limitam a formas bem conhecidas de pensar e agir”. Para Nonaka e Takeuchi (1997), indivíduos, grupos e organizações se recriam destruindo o sistema de conhecimento existente e encontrando novas formas de pensar e fazer as coisas, o que remete ao processo "schumpeteriano" de destruição criadora.

Para Filion (1991, p. 64), os empreendedores aprendem com a experiência passada e atual, tendo postura proativa, pois devem "[...] identificar coisas novas que deverão aprender, tendo em vista as coisas novas que desejam realizar". Vale salientar, também, a importância da aprendizagem informal, que às vezes parece ser mais importante que o ensino formal (FILION, 1999a). Por vezes, a aprendizagem de empreendedores ocorre muito mais pelo "ver" do que pelo "ler", mais pela intuição do que pela escolarização. 
A aprendizagem vem sendo crescentemente apontada como fonte de competitividade, nas esferas individual, grupal, organizacional e interorganizacional (BELL e PAVITT, 1993; TEIXEIRA e GUERRA, 2001). A aprendizagem de empreendedores, em um contexto em que processos produtivos sofrem alterações e transformações propiciadas por inovações nas tecnologias de informação e comunicação, é instrumento para a construção de novas competências que levam a vantagens competitivas. De acordo com Lundvall et al. (2002), a rápida e contínua mudança técnica provoca a formação e destruição do estoque de conhecimento especializado, exigindo uma contínua capacidade de aprendizado.

Processo fundamental para a construção de novas competências e obtenção de vantagens competitivas, pela repetição, experimentação, busca de novas fontes de informação e outros mecanismos, o aprendizado capacita e estimula atividades produtivas e inovadoras. $\mathrm{O}$ empreendedor não compete reproduzindo o que seus rivais fazem, mas sendo diferente e obtendo ganhos com essa diferença.

Uma das mais significativas maneiras de aprendizagem de empreendedores ocorre pela via da rede de relações. Os empreendedores precisam desenvolver redes de relacionamento e de cooperação com indivíduos que consideram estratégicos, pois as redes possibilitam a ocorrência de diálogos lapidares (breves, concisos) e eficientes. Sem as redes, essas interações breves, mas significativas, não seriam possíveis (KOTTER, 2000).

\section{Rede de relações}

Etimologicamente a palavra "rede" é derivada do latim rete, que significa entrelaçamento de fios, cordas, cordéis, arames, com aberturas regulares fixadas por malhas, formando uma espécie de tecido. Uma rede "[...] é o conjunto de pessoas com as quais o ato de manter relações de amizade ou de camaradagem permite conservar e esperar confiança e fidelidade. [...] essas redes, tradicionais ou modernas, são alianças generalizadas criadas na aposta na dádiva e na confiança" (CAILLÉ, 2002, p. 65).

O tecido social é composto por redes. Atuando em conjunto, os homens formam redes formais e informais. A palavra rede é usada metaforicamente, pois é suficientemente clara para transmitir a ideia de pessoas que se comunicam, tendo pontos que podem ser considerados de ligação para determinados assuntos.

Segundo Castells (2003, p. 108), uma rede "[...] pode ser implementada materialmente em todos os tipos de processos e organizações. [...] A lógica das redes é necessária para estruturar o não-estruturado, porém, preservando a flexibilidade, pois o não-estruturado é a força motriz da inovação na atividade humana". $\mathrm{O}$ não-estruturado baseia-se fundamentalmente na confiança como fonte de redução da incerteza. Por intermédio das redes voltadas ao bem comum, de caráter coletivo, constrói-se o capital social.

As redes, de acordo com Elias (1994), formam uma ponte entre indivíduos e sociedade; ação e estrutura. O autor propõe a noção de redes de funções como uma perspectiva que procura ultrapassar a dualidade indivíduo versus sociedade, realçando a interdependência entre estes elementos.

De acordo com Granovetter (1992), as redes são formadas por laços que podem ser fortes, fracos ou ausentes. O que caracteriza a intensidade do laço é a combinação entre tempo, intensidade emocional, confiança mútua e serviços recíprocos.

Em relação à circulação de informações nas redes, Burt (1992), concordando com Granovetter (1992), aponta que, nos laços fortes, a informação tende à redundância; enquanto nos laços fracos, é maior a probabilidade de que circulem informações novas e diferentes. Segundo Castells (2003, p. 222), "[...] as informações circulam pelas redes: redes entre empresas, redes dentro de empresas, redes pessoais e redes de 
computadores". As redes são formadas por meio dos papéis, atribuições e relações entre seus atores; e suas vantagens concentram-se na propagação de informações, na aquisição de recursos e na possibilidade de alcançar vantagens (BURT, 1992).

A formação de uma rede de empreendedores e/ou de empresas é uma nova arquitetura que pode ter nascido e vem se desenvolvendo com a chamada visão empreendedora. De acordo com Filion (1999a), para os empreendedores, o processo de criar e definir uma arquitetura de negócios está baseado no espaço que pretendem ocupar; eles identificam um nicho e visualizam a estrutura e os recursos necessários para ocupálo.

Filion (1991, p. 69) considera que "[...] as relações e as visões dão origem às ações; as ações requerem, frequentemente, o estabelecimento de novas relações, que por sua vez, influenciam o surgimento de novas visões". O autor aponta que as redes de relações podem ser o principal elemento de suporte para a evolução de uma visão de negócios e identifica três níveis de relações mantidas pelos empreendedores, conforme pode ser observado na Tabela 2.

Tabela 2

\section{Níveis de relações}

\begin{tabular}{|l|l|}
\hline \multirow{2}{*}{ PRIMÁRIO } & Familiares \\
\cline { 2 - 3 } & Ligações em torno de mais de uma atividade \\
\hline \multirow{3}{*}{ SECUNDÁRIO } & Conhecidos \\
\cline { 2 - 3 } & Ligação em torno de uma atividade bem determinada \\
\cline { 2 - 3 } & Rede de ligações \\
\hline \multirow{2}{*}{ TERCIÁRIO } & Cursos \\
\cline { 2 - 3 } & Livros, viagens, feiras e exposições industriais \\
\hline
\end{tabular}

Fonte: Filion, 1991, p. 68.

De acordo com o autor, o nível primário é responsável pela visão inicial ou emergente e os níveis seguintes levam à visão central, que indica ao empreendedor o que deve ser feito, possibilitando-lhe evoluir da concepção para a realização de um projeto (FILION, 2004). Ou seja, a visão é um tipo de auto-orientação que caracteriza o fenômeno empreendedor. Em relação à visão secundária, pode-se considerar a ligação em torno de uma atividade bem determinada ligada ao processo de mentoria. Robbins (2005) aponta que um mentor compartilha experiências, age como um modelo, divide contatos e orienta seu "protegido" nos meandros da política. 


\section{Visão}

De acordo com Filion (1991, p. 64), o empreendedor é "[...] alguém que concebe, desenvolve e realiza visões", alguém que planejadamente passa por uma sequência de empregos com o objetivo de acumular experiência e conhecimento em um processo dinâmico de aprendizagem. Metaforicamente, a visão é como "uma luz no fim de um labirinto". O empreendedor desenvolve, pois, um senso de direção, identifica percursos alternativos e desenvolve flexibilidade e facilidade de adaptação (MINTZBERG, AHLSTRAND e LAMPEL, 2000).

A visão empreendedora atua como uma diretriz, fornecendo indicadores para o empreendedor organizar e desenvolver suas atividades. Depois de imaginada, “[...] a visão é desenvolvida, corrigida e ajustada, não em termos de seu conteúdo básico, mas em termos das muitas atividades diferentes necessárias para que se prossiga na concretização da visão. A visão não é estática, ela é um processo em constante evolução" (FILION, 1999a, p. 12).

A visão é dividida por Filion (1993) em três categorias, conforme Tabela 3.

Tabela 3

\section{Categorias de visão}

\begin{tabular}{|l|l|l|}
\hline Visão inicial & \multicolumn{2}{|l|}{ Ideias para produtos ou serviços futuros } \\
\hline Visão central & $\begin{array}{l}\text { Resultante de uma ou mais visões } \\
\text { emergentes }\end{array}$ & $\begin{array}{l}\text { Parte externa: a faixa de mercado a ser } \\
\text { ocupada por um produto ou serviço } \\
\text { Parte interna: tipo de organização } \\
\text { necessária para realizar a parte externa }\end{array}$ \\
\hline Visão complementar & Atividades gerenciais necessárias para dar suporte à visão central \\
\hline
\end{tabular}

Fonte: Adaptado de Filion, 1993, 1999a.

A visão central geralmente ocorre após várias visões emergentes ou iniciais, influenciadas pelo nível primário de relações. É por meio da visão central que empreendedores projetam e criam novos negócios. Assim, a visão é entendida por Filion (1999a, p. 10) como "[...] uma imagem projetada de uma situação de futuro desejada - um sonho realista e alcançável". O autor indica que "[...] a visão é uma projeção: uma imagem, projetada no futuro, do lugar que o empreendedor deseja que seu produto venha a ocupar no mercado. É, também, uma imagem do tipo da empresa necessária para alcançar esse objetivo. Em suma, visão refere-se a onde o empreendedor deseja conduzir seu empreendimento" (FILION, 1993, p. 52).

Após localizar um nicho, o empreendedor precisa "[...] ter uma visão de alguma coisa ou algum lugar a ser ocupado no mercado e saber qual é o tipo de organização necessária para tornar isso realidade" (FILION, 2000, p. 4). De acordo com Paiva Jr. (2004, p. 270), "ser empreendedor é acreditar na visão maior, ser obstinado na ação e discernir acerca das demandas do ambiente". 
Segundo Metcalfe (2005, p. 402), “[...] o que há de singular em cada empreendedor é que ele discerne uma visão diferente do mundo, uma visão que é a base da ação econômica diferenciada". Eles creem em algo em que ninguém mais crê, com força suficiente para agir com base nessa crença e alocar recursos econômicos num projeto, de forma imaginativa e diferenciada, definindo sua própria estrutura de trabalho. Para Filion (2000), a atividade empreendedora está intimamente ligada à maneira de interpretar o que está acontecendo em um setor particular do meio.

A visão é sustentada, de acordo com Filion (1991), por quatro elementos que se influenciam reciprocamente:

- rede de relações: parece ser o elemento mais influente na evolução da visão empreendedora. As relações primárias (familiares) moldam a visão inicial ou emergente e as relações secundárias e terciárias influenciam o desenvolvimento das visões subsequentes (complementar e central). Por sua vez, quanto mais articulada a visão, mais importante será o seu papel na escolha dos critérios para o estabelecimento de novas relações, numa inter-relação recíproca;

- weltanschauung: maneira pela qual o indivíduo vê o mundo real, identificando o que é significativo. Valores, atitudes, humor e intenções subjacentes à percepção estão relacionados a esse elemento. A weltanschauung não é estática e definitiva, evolui continuamente, sendo influenciada pelo contexto em que o empreendedor age ou pretende agir;

- energia: está relacionada ao tempo reservado para as atividades profissionais e a intensidade com que estas são realizadas. Quanto mais tempo e energia forem despendidos no desenvolvimento da visão, tanto mais benefícios o empreendedor receberá, porque as diretrizes desenvolvidas vão gerar motivação e energia naqueles que estão próximos e são influenciados pela liderança empreendedora;

- liderança: resultante das relações, da weltanschauung e da energia. Sua importância para o desenvolvimento da visão decorre do seu impacto sobre o nível da visão e da extensão daquilo que o empreendedor pretende realizar. A liderança pode surgir numa evolução gradual, que requer a aquisição de uma habilidade particular num setor particular de atividade. A habilidade para desenvolver a visão parece conferir liderança; e esta, para o empreendedor, provavelmente depende do desenvolvimento da visão.

A importância da liderança é enfatizada por Filion (1999a) ao indicar que as pessoas próximas ao empreendedor é que possibilitarão a realização e o desenvolvimento da visão. A visão, juntamente com as atividades necessárias para torná-la realidade, são critérios implícitos para a escolha dos colaboradores, que influenciam diretamente no sucesso do empreendimento.

Na função empreendedora, de acordo com Metcalfe (2005, p. 400), o que há de singular é a liderança nos negócios, pois ela abrange, "[...] necessariamente, a capacidade de reunir os recursos produtivos necessários, o contato com os consumidores potenciais e a organização da empresa".

Mintzberg; Ahlstrand e Lampel (2000) entendem a visão como um sentido do que precisa ser feito, uma ideia guia, criada ou, pelo menos, disseminada pelo líder. De acordo com Filion (2004) a ação empreendedora é visionária; assim, geralmente, empreendedores comportam-se como líderes visionários.

A visão não deve ser entendida como processo místico e irracional. Filion (1999a) sustenta que empreendedores têm "sonhos realistas" ou visões e estão sempre comprometidos com a realização destas. A visão é uma condição vital para empreendedores. 


\section{Inovação}

Segundo Schumpeter (1988), empreendedorismo é a atividade de efetuar inovações, e a função inovadora promove mudanças, combinando recursos de maneira diferenciada e original, bem como o desenvolvimento e o crescimento econômico. Inovações fazem parte do processo de destruição criadora, que pode ser entendido como mutação industrial que revoluciona a estrutura econômica de forma endógena, destruindo a ordem vigente e criando uma nova ordem (SCHUMPETER, 1988).

Inovação é a tentativa de criação de um espaço novo para valorizar o capital. Tal espaço necessita permanecer como monopólio da firma inovadora por algum tempo (elevada apropriação) para garantir lucratividade. Isso pode ocorrer por meio de um novo produto, processo, mercado, forma de organização (POSSAS, 2002).

Morton apud Almeida (1986) destaca que a inovação não é uma ação simples, mas um processo global, composto de partes interconectadas. Não é somente a descoberta de um fenômeno novo, nem o desenvolvimento de um novo produto ou procedimento de fabricação, nem a criação de um novo mercado. É, sobretudo, a conjunção estreita de um conjunto integrado de ações dirigidas para um objetivo comum. Às vezes, empreendedores não introduzem qualquer fenômeno novo ou inovação importante de mercado, porém, inovam ao reduzir custos, ao melhorar a qualidade ou oferecer serviços mais rápidos (FILION, 1999a).

As ondas de desenvolvimento pelas quais a humanidade vem passando foram grandemente baseadas na introdução de inovações radicais. As mudanças tecnológicas foram, assim, responsáveis por transformações estruturais da economia e da sociedade, alterando padrões de consumo e produção, geração e distribuição de renda (ARBIX e MENDONÇA, 2005).

A inovação é um processo cumulativo e coletivo e mantém vínculos estreitos com a concentração espacial, tendo como

[...] elementos centrais o aprendizado e a interação entre diferentes e numerosos agentes, que se beneficiam inegavelmente da proximidade geográfica, já que requer não apenas troca constante e direta de conhecimento entre agentes distintos e complementares, como também é função de códigos, práticas valores, sanções sociais, relações de confiança entre sujeitos que premiam a geração e difusão de novos conhecimentos práticos e conceituais. (FERNANDES e LIMA, 2006, p. 17).

Deve-se salientar que a construção de sistemas de inovação envolve empresas, instituições de ensino e pesquisa, além de interação entre empreendedores, nos âmbitos nacional, regional e local, e ocorre através de aprendizagem (FREEMAN, 1995).

\section{Procedimentos Metodológicos}

Cada vez mais, recursos estéticos como filmes, romances, música e fotografias vêm sendo utilizados no processo de ensino-aprendizagem, pois podem facilitar a construção de um link entre construtos teóricos e realidade prática. A observação é o método apropriado, de acordo com Cooper e Schindler (2003), para a análise de recursos estéticos, pois, além de possibilitar a coleta de dados visuais, envolve também a audição, o olfato e o tato. 
Em relação ao uso de filmes como material empírico nas ciências sociais, Denzin (2004) indica um conjunto de princípios organizativos para a pesquisa de documentos visuais, embora saliente que estes devam ser adaptados às necessidades do pesquisador.

Nesta pesquisa, foram seguidas as quatro fases indicadas pelo autor: 1) olhar e sentir, procurando identificar padrões de significado e registrar as impressões; 2) formular a pergunta de pesquisa ou o objetivo; 3) realizar uma microanálise cena a cena, descrevendo-as detalhadamente; e 4) após ver o filme quantas vezes necessárias, descrever os dados observados de forma a atingir o objetivo proposto.

Há uma diferença significativa entre o ato de observar rotineiramente a realidade e a interação com o mundo e o de examinar com "olhos clínicos"; isto é, observar apurada e sistematicamente para coletar dados (MERRIAM, 1998). A observação com "olhos clínicos" é "[...] a base de toda investigação no campo da ciência social, podendo ser utilizada em trabalho científico de qualquer nível, desde os mais simples estágios até os mais avançados" (RICHARDSON, 1999, p. 259).

Para que a observação se caracterize como investigação científica, deve obedecer a alguns critérios: ser conduzida especificamente para responder a uma questão de pesquisa, ser sistematicamente planejada, executada e registrada, usar controles apropriados e fornecer informações válidas e confiáveis sobre o objeto de estudo (COOPER e SCHINDLER, 2003; SELLTIZ et al., 1987).

Patton (2002) classifica o papel do observador propondo um continuum entre participação total e participação como espectador. Na participação total, a observação é participante; na participação como espectador, como no estudo observacional, o pesquisador desempenha apenas o papel de observador. Mesmo na participação como espectador, é possível ao pesquisador descrever locus, atividades e significados do que está sendo observado.

Como o observador não estava fisicamente presente, pode-se considerar também que foi realizada uma observação indireta, que é "[...] menos flexível do que a observação direta, mas também é muito menos tendenciosa e pode ser muito mais acurada. Outra vantagem da observação indireta é que o registro permanente pode ser reavaliado para incluir vários aspectos diferentes do fato" (COOPER e SCHINDLER, 2003, p. 307).

Tomando como base o contínuo participante/observador proposto por Bogdan e Biklen (1994), foi priorizada a posição de "observador completo"; ou seja, "[...] o investigador não participa em nenhuma das actividades do local onde decorre o estudo. Olha para a cena, no sentido literal [...]" (BOGDAN e BIKLEN, 1994, p.125).

Como o objetivo deste trabalho foi analisar as características empreendedoras de Irineu Evangelista de Souza presentes no filme "Mauá - O Imperador e o Rei" por meio de uma abordagem qualitativa e da utilização de métodos visuais, pode-se considerar que foi feito um estudo observacional, com o observador como espectador (PATTON, 2002) ou observador completo (BOGDAN e BIKLEN, 1994), pois o tipo de observação foi de segunda mão (FLICK, 2004) e indireta, o que possibilita ao pesquisador observar diversas vezes o locus (filme). Neste estudo observacional, o filme foi exibido cinco vezes para a equipe, com um intervalo de uma semana entre cada exibição, com discussão posterior para identificar as características empreendedoras do "barão" com base nos estudos de Filion. Os membros da equipe assistiram ao filme individualmente ou em pequenos grupos quantas vezes consideraram necessário. 


\section{O Estudo Observacional}

Irineu Evangelista de Sousa nasceu em 28 de dezembro de 1813, no Rio Grande do Sul. Aos seis anos de idade, perdeu o pai, assassinado por um tropeiro. Viúva aos 28 anos e com poucos recursos, a mãe conheceu, dois anos depois, um pretendente que lhe impôs como condição ao casamento que afastasse as crianças. A solução encontrada foi casar a filha Guilhermina aos dez anos de idade e entregar Irineu ao tio José Baptista de Sousa, capitão de um navio, que o trouxe para o Rio de Janeiro.

Na então capital do país, o tio consegue moradia e alimentação para o garoto em troca de trabalho no armazém do seu Pereira. Um dos maiores comerciantes do império, João Rodrigues Pereira de Almeida era um atacadista que importava diversos gêneros, inclusive mão de obra escrava.

Com a situação econômica da época agravada pela Confederação do Equador e pela guerra contra a Argentina, os negócios do senhor Pereira entram em crise, impossibilitando o pagamento dos credores. Irineu, que já se tornara o "caixeiro" da firma, propõe ao comerciante que o deixe negociar tanto com seus devedores (fazendeiros que têm dívidas com tráfico de escravos), quanto com seus credores. Negociador implacável, consegue recuperar débitos para providenciar o pagamento dos credores, entre os quais está um escocês que fez fortuna no Brasil, Richard Carruthers.

Observando o desempenho de Irineu, Carruthers o convida para trabalhar em seu escritório, cujo negócio "é ganhar dinheiro". No ano de 1836, Irineu é convidado a tornar-se sócio de Carruthers, que retorna à Escócia e o deixa tocando o negócio no Brasil. Mesmo distante geograficamente, continua aconselhando, orientando e indicando a Irineu o que deve ser feito, levando-o a evoluir da concepção para a realização de projetos (FILION, 2004),

Aos 23 anos, Irineu já pode ser considerado um veterano no mundo dos negócios, exceção ao que Holanda (1995, p. 59) considera que faltou ao Brasil em relação aos ofícios e ao verdadeiro artesanato, "[...] foi, seguramente, uma capacidade de livre e duradoura associação entre os elementos empreendedores do país". Pode-se considerar que Carruthers foi o mentor de Irineu, pois, a partir da sociedade com ele, os negócios crescem e Irineu decide investir na área industrial, comprando, em 1846, o Estabelecimento de Fundição e Estaleiro Ponta de Areia, em Niterói.

Em curto espaço de tempo, um empreendimento praticamente falido torna-se a maior fundição do país, empregando aproximadamente mil trabalhadores livres. Após quatro anos, funda a Companhia de Rebocadores Barra do Rio Grande e torna-se importador de tecidos e ferragens inglesas, exportador de café, fumo e açúcar e concessionário de serviços públicos. Já milionário, Irineu ganha a concorrência para fornecer iluminação pública ao Rio de Janeiro e a concessão exclusiva, por 30 anos, para lançar a Companhia de Navegação a Vapor do Amazonas.

$\mathrm{Na}$ área financeira, em 1851, funda o primeiro banco de porte do país, o Banco do Commércio e da Indústria do Brasil, em sociedade com outros comerciantes e negociantes. Como o Banco do Brasil, fundado em 1808 por D. João VI, havia falido, o banco fundado por Irineu ficou mais conhecido como o segundo Banco do Brasil.

A economia brasileira era agroexportadora e, para levar as commodities do campo ao porto, Irineu constrói a primeira ferrovia do país, ligando o Porto de Estrela, hoje Porto Mauá, à localidade de Raiz da Serra, na região serrana do Rio de Janeiro. Para realizar a primeira viagem, foram convidados o imperador D. Pedro II, a família real e diversas autoridades. Neste ensejo, D. Pedro concedeu-lhe o título de Barão de Mauá. 
Em sociedade com banqueiros ingleses, o Barão funda mais um empreendimento, o Banco Mauá, McGregor \& Cia, que, em pouco tempo, abre agências em Londres, Paris, Manchester, Nova York, Buenos Aires, Rosário, Córdoba e Montevidéu. Em 1860, Mauá inicia mais um grande investimento, a construção da Estrada de Ferro Santos-Jundiaí, em sociedade com o banco Rothschild \& Sons.

Na década de 1860, Irineu Evangelista de Sousa era o homem mais rico do Brasil e, no seu apogeu, ocorrido ao redor de 1867, o valor total dos seus ativos contabilizava 115 mil contos de réis, quando o orçamento do Império de D. Pedro II era de 97 mil contos de réis (BERTERO e IWAI, 2005).

No século XIX, a educação no Brasil era exclusiva para os filhos da elite, mas Irineu torna-se autodidata. Ainda muito jovem, é surpreendido pelo patrão, o seu Pereira, lendo um livro à luz de vela. Questionado, informa que está lendo Princípios de Economia Política, do Visconde de Cairu. Filion (1993) afirma que quanto mais jovem o empreendedor escolher o que fazer, melhor poderá trabalhar seu Weltanschauung, ou a imagem que ele quer realizar.

Filion (1991) aponta que o empreendedor passa planejadamente por uma sequência de empregos com o objetivo de acumular experiência e conhecimento, em um processo dinâmico de aprendizagem. Quando o jovem Irineu aceita o convite de Carruthers para trabalhar em sua empresa, pode-se observar que seu objetivo é aprender.

No novo emprego Irineu estuda por conta própria a língua inglesa. Continua suas leituras sobre economia e, por meio da observação, aprende como funciona o mercado e o que seria necessário para desenvolvê-lo. $\mathrm{O}$ trabalho com Carruthers lhe proporciona maiores oportunidades de conhecer a realidade da Inglaterra e seu vigor industrial. Muitas vezes, a aprendizagem de empreendedores acontece mais por meio de "ver" do que pelo "ler", mais pela intuição do que pela educação formal, e, também, observando os mais experientes. Durante todo o filme, observa-se que, antes de iniciar um negócio, Irineu sempre procurava os conselhos de seu amigo e sócio escocês.

De acordo com Filion (1991), as relações e as visões originam ações, e estas requerem, frequentemente, que se estabeleçam novas relações, que, por sua vez, influenciam o surgimento de novas visões. $\mathrm{O}$ autor aponta que as redes de relações podem ser o principal elemento de suporte para a evolução de uma visão de negócios. Na Tabela 4, podem-se identificar os três níveis de relações mantidas por Mauá.

Tabela 4

\section{Níveis de relações mantidas por Mauá}

\begin{tabular}{|l|l|}
\hline \multirow{2}{*}{ PRIMÁRIO } & Casa-se com a filha de sua irmã \\
\hline \multirow{2}{*}{ SECUNDÁRIO } & Sr. Carruthers, Paranhos, Visconde de Uruguai \\
\cline { 2 - 3 } & Ingressa na maçonaria \\
\hline TERCIÁRIO & Leitura constante de livros de economia, viagens à Inglaterra \\
\hline
\end{tabular}

Fonte: elaborada pelas autoras, 2009. 
Apesar de ter construído sua rede de relações, Mauá era homem de poucos amigos, o que remete a Granovetter (1992), quando este afirma que, nos laços fortes, a informação tende à redundância, enquanto nos laços fracos podem circular informações novas e diferentes. Pode-se considerar a maçonaria como uma rede secundária, caracterizada por um laço fraco, e da qual Mauá recebia muitas informações, inclusive o que atualmente é considerada "informação privilegiada". Quanto ao nível de relação terciário, identifica-se claramente a leitura constante e as viagens à Inglaterra.

Ainda quanto à rede de relações, Irineu, desde jovem, baseava seus relacionamentos na confiança, tanto que, ao ser encarregado de alimentar os escravos confinados, entrega a chave da máscara a Valentim, que está sendo punido por consumir bebida alcoólica. O modelo de cobrança que adotou para recuperar dinheiro dos devedores de seu patrão, Sr. Pereira, bem como para pagar os credores, foi negociar prazos que deveriam ser rigorosamente cumpridos, com lastro apenas na confiança entre as partes.

Filion $(1991,2004)$ considera que o nível primário de relações é responsável pela visão inicial ou emergente e os níveis seguintes levam à visão central, que indica ao empreendedor o que deve ser feito, levando-o a evoluir da concepção para a realização de um projeto.

A visão é um processo racional e ao mesmo tempo intuitivo, e adquirida pela análise do ambiente. Torna o empreendedor capaz de perceber oportunidades, de enxergar ganho onde outros percebem perda e prejuízo. Desde cedo, a visão caracteriza o comportamento empreendedor de Mauá. Em uma conversa informal, seu Pereira comenta sobre papéis do Banco do Brasil que considera sem valor. Irineu, confiando na instituição, propõe comprar estes papéis, com suas economias, por 30\% do valor nominal. Mesmo avisando a Irineu sobre o péssimo negócio que está fazendo, vende os papéis por $20 \%$ do valor. Posteriormente, o Banco do Brasil resgata os papéis e Irineu ganha um bom dinheiro.

Carruthers identifica em Irineu um empreendedor e, voltando para a Europa, deixa-o como sócio da empresa. Com base em análises do mercado, o novo sócio aumenta significativamente os lucros da companhia no Brasil.

Com 27 anos Irineu faz sua primeira viagem à Inglaterra e fica deslumbrado com a indústria têxtil. Apesar das péssimas condições de trabalho dos operários, acredita firmemente que, por serem livres, podem lutar para alterar tal situação. Irineu propõe ao sócio a venda da Carruthers and Company, pois tem a informação de que o governo brasileiro não iria renovar o acordo comercial com a Inglaterra. A Coroa brasileira estava implantando a Tarifa Alves Branco, que taxava a importação de determinados produtos entre $30 \%$ e $60 \%$.

O anúncio de liquidação da Carruthers \& Co. surpreende a todos, pois quebra um paradigma: a empresa não está em situação falimentar, pelo contrário, está muito bem financeiramente. Irineu deixa de ser um comerciante para se tornar um industrial. Compra o Estabelecimento de Fundição e Estaleiro Ponta de Areia, em Niterói. De uma situação de abandono, Ponta de Areia tornou-se a maior empresa de fundição do país; empregava, aproximadamente, mil trabalhadores livres e assalariados e produzia canos, barcos, navios, canhões, guindastes, postes, caldeiras, etc.

A visão de Mauá estendia-se também à esfera política e, em razão disso, financiou a manutenção de um governo no Uruguai para agradar ao imperador D. Pedro II, pois a Coroa brasileira não poderia se envolver diretamente no conflito. Apesar de Mauá perceber tal investimento como de risco, empregou recursos próprios, possivelmente para manter a rede de relações que tinha com o governo. A capacidade para correr riscos é inerente ao perfil empreendedor, como constatado nos estudos de Scarborough e Zimmerer (2000) e Hitt, Ireland e Hoskisson (2003). 
Pode-se considerar também que Mauá tinha uma visão social, pois muito jovem decidiu que nunca teria um escravo. Dono de diferentes tipos de negócio e proprietário de terras, jamais utilizou mão de obra escrava.

O notório conhecimento acumulado na área de negócios levou Mauá a participar da redação do Código Comercial Brasileiro, promulgado em 25 de junho de 1850 pelo imperador D. Pedro II. Este código trouxe uma grande inovação: a partir daquela data as mulheres maiores de 18 anos poderiam abrir seu próprio estabelecimento comercial.

Schumpeter (1988) considera que o papel do empresário inovador é o de quebrar paradigmas na economia de mercado, o que Mauá fez com mestria. Construiu ferrovias, quando a locomotiva movida a vapor era ainda uma novidade no Brasil, trouxe a iluminação pública para o Rio de Janeiro, viabilizou a construção do primeiro cabo submarino ligando o Brasil à Europa e, principalmente, sempre defendeu a força da indústria como motor da economia em um país que considerava, como sua vocação natural, a agricultura. D. Pedro II concedeu-lhe o título de Visconde de Mauá, em 1874, após a instalação do cabo submarino.

Em sua visita ao Barão, Bertero e Iwai (2005) analisam as estratégias utilizadas por ele nos negócios e constatam que suas ações empresariais foram equivocadas do ponto de vista atual sobre estratégia, pois suas relações com a ordem institucional eram ambíguas, tendo buscado parceria para garantir concessões, diluir risco e financiar empreendimentos. Ora, o risco, de acordo com Schumpeter (1988), deve ser assumido pelo capitalista, que vem a ser o indivíduo que concede o crédito. Havia, sim, uma reciprocidade, que fica bem clara quando o Barão destina recursos próprios, no conflito do Uruguai, para "isentar" o governo brasileiro de qualquer envolvimento.

Como aponta Barman (1981), o governo brasileiro teve uma posição restritiva e de definitiva hostilidade quando, em 1875, negou o empréstimo de três mil contos solicitado pelo Banco Mauá \& Cia. A solução foi solicitar moratória por três anos, período no qual Mauá saldou dois terços de seu passivo. Transcorridos os três anos, Mauá procurou renegociar o restante da dívida, mas não foi atendido e praticamente todos os seus bens entraram na conta dos débitos.

Não havia uma situação de dependência em relação ao poder público e nem qualquer protecionismo do Estado, muito pelo contrário, a decretação da falência dos negócios do então Visconde, em 1878, ocorreu porque o governo não renegociou as dívidas que Irineu vinha lutando para saldar desde a declaração da moratória da Mauá \& Cia, em 1874. Quem sempre teve uma posição ambígua em relação a Irineu Evangelista de Sousa foi o governo brasileiro, e não o contrário.

\section{Considerações Finais}

O objetivo deste trabalho foi analisar as características empreendedoras de Irineu Evangelista de Sousa, presentes no filme "Mauá - O Imperador e o Rei". Procurou-se usar como base argumentativa o trabalho de Louis Jacques Filion (2004, 2000, 1999, 1993, 1991) sobre características empreendedoras básicas inovação, aprendizagem, rede de relações e visão.

O perfil de Irineu apresentava com vigor todas as características do comportamento empreendedor propostas na tipologia de Filion (1991). De menino pobre, tornou-se o empresário mais rico do Brasil, aprendendo sempre, construindo uma rede de relações, visualizando o futuro e quebrando paradigmas na economia de mercado ao apresentar inovações técnicas e sociais. 
Mauá (1996) redigiu uma exposição de motivos aos credores e ao público relatando a trajetória de seus empreendimentos e analisando as causas de sua falência. Procurava justificar que não tinha sido imprevidente na condução de seus negócios e nem havia falhado em gerenciá-los, mas, antes, tinha sido prejudicado pelo governo brasileiro em conjunto com a elite conservadora, que considerava danosas ao país as atitudes empreendedoras.

Tivesse sido implantado o projeto de futuro de Mauá, talvez fosse outra a história do Brasil. O país não teria tido uma industrialização tão tardia: somente em 1928 a renda industrial superaria, pela primeira vez, a renda agrária (COTRIM, 1995).

Irineu Evangelista de Sousa foi o maior proprietário de terras do Brasil, banqueiro, industrial e empreendedor em uma época em que a elite brasileira se orgulhava pelo fato de não trabalhar, herança da cultura ibérica, que priorizava o ócio em detrimento do negócio e em "[...] que a atividade produtora era, em si, menos valiosa que a contemplação e o amor" (HOLANDA, 1995, p. 38). Mauá teve encerrado, por ingerências políticas, o sonho de ver a economia do país movida por um parque industrial competitivo, por um sistema financeiro sólido e confiável e pela livre iniciativa.

Com este estudo observacional, espera-se resgatar a figura de um brasileiro cujos feitos os livros de história mostram com superficialidade, deixando uma lacuna no conhecimento sobre empreendedores brasileiros.

\section{Referências}

APOSPORI, E.; PAPALEXANDRIS, N.; GALANAKI, E. Entrepreneurial and professional CEOs: differences in motive and responsibility profile. Leadership \& Organization Development, v. 26, p. 141-162, 2005.

ARBIX, G.; MENDONÇA, M. Inovação e competitividade: uma agenda para o futuro. In: CASTRO, A. C.; LICHA, A.; PINTO JR., H. Q.; SABOIA, J. (Orgs.). Brasil em desenvolvimento. Rio de Janeiro: Civilização Brasileira, 2005.

BARMAN, R. J. Business and government in imperial Brazil: The experience of Viscount Maua. Journal of Latin American Studies, v. 13, n. 2, 1981.

BAUMOL, W.J. Entrepreneurship, management and the structure of payoffs. Boston: MIT Press, 1993.

BELL, M.; PAVITT, K. Accumulating technological capability in developing countries. In: ANNUAL CONFERENCE ON DEVELOPMENT ECONOMICS, 1993, Washington/DC. Proceedings...Washington: The World Bank, 1993.

BERTERO, C. O.; IWAI, T. Uma Visita ao Barão. Revista de Administração Contemporânea, Curitiba, v. 9, número especial, p. 1-17, 2005.

BOGDAN, R.; BIKLEN, S. Investigação qualitativa em educação - Uma introdução à teoria e aos métodos. Porto: Editora Porto Ltda., 1994.

BURT, R.S. Structural holes: the social structure of competition. Cambridge: Harvard University Press, 1992.

CAILLÉ, A. Dádiva e associação. In: MARTINS, P. H. (Org.). A dádiva entre os modernos: discussão sobre os fundamentos e as regras do social. Petrópolis: Vozes, 2002.

CASSON, M. The entrepreneur: An economic theory. Totowa, New Jersey: Barnes \& Noble Books, 1982. 
CASTELLS, M. A sociedade em rede - A era da informação: economia, sociedade e cultura; v. 1. $7^{\mathrm{a}}$ ed. São Paulo: Paz e Terra, 2003.

COOPER, D. R.; SCHINDLER, P. S. Métodos de pesquisa em Administração. 7. ed. Porto Alegre: Bookman, 2003.

CORÓ, G. Distritos e Sistemas de Pequenas Empresas. In: COCCO, G.; URANI; A.; GALVÃO, A. P. (Orgs.). Empresários e Empregos nos Novos Territórios Produtivos - o caso da Terceira Itália. Rio de Janeiro: DP\&A, 1999.

COTRIM, G. História e consciência do Brasil. 2. ed. São Paulo: Saraiva, 1995.

COUTINHO, M. C. Espaço e Economia no Sistema de Cantillon. Nova Economia, Belo Horizonte, v. 15, n. 1, p. $97-$ 116, jan./abr. de 2005.

DENZIN, N. K. Reading Film: Using films and videos as empirical social science material. In: FLICK, U.; KARDORFF, E. von; STEINKE, I. A companion to Qualitative Research. California: Sage Publications Inc., 2004.

DRUCKER, P. F. Inovação e espírito empreendedor (Entrepreneurship): prática e princípios. São Paulo: Pioneira, 1986.

. Sociedade Pós-capitalista. São Paulo: Pioneira, 1994.

FERNANDES, A. C.; LIMA, J. P. R. Cluster de Serviços: contribuições conceituais com base em evidências do pólo médico do Recife. Nova Economia (UFMG), v. 16, p.11-48, 2006.

FILION, L. J. O planejamento do seu sistema de aprendizagem empresarial: identifique uma visão e avalie o seu sistema de relações. Revista de Administração de Empresas, São Paulo, v. 31, p. 63-71, jul./set. 1991.

. Visão e relações: elementos para um metamodelo empreendedor. RAE Revisitada, São Paulo, v. 33, n. 6, p. 50-61, nov./dez. 1993.

Diferenças entre sistemas gerenciais de empreendedores e operadores de pequenos negócios. Revista de Administração de Empresas, São Paulo, v. 39, n. 4, p. 6-20, out./dez. 1999a.

Empreendedorismo: empreendedores e proprietários-gerentes de pequenos negócios. Revista de Administração de Empresas, São Paulo, v. 34, n. 2, p. 05-28, abr/jun. 1999b.

Empreendedorismo e gerenciamento: processos distintos, porém complementares. RAE Light, São Paulo, v. 7, n. 3, p. 2-7, jul./set. 2000.

2004.

Entendendo os intraempreendedores como visionistas. Revista de Negócios, Blumenau, v. 9, n. 2, abr./jun.,

FLICK, U. Uma introdução à Pesquisa Qualitativa. Porto Alegre: Bookman, 2004.

FREEMAN, C. The 'National System of Innovation' on historical perspective. Cambridge Journal of Economics. Cambridge, v. 19, p. 5-24, Academic Press Limited, 1995.

GRANOVETTER, M. Economic Action and Social Structure: The Problem of Embeddedness. In: GRANOVETTER, M.; SWEDBERG, R. The Sociology of Economic Life. San Francisco: Westview Press, 1992.

HAMEL, G.; PRAHALAD, C. K. Competindo pelo Futuro. São Paulo: Campus, 1995.

HITT, M. A.; IRELAND, R. D.; HOSKISSON, R. E. Administração Estratégica. São Paulo: Thomson, 2003. 
HOLANDA, S. B. de. Raízes do Brasil. 26.ed. São Paulo: Companhia das Letras, 1995.

KAO, J. J. Entrepreneurship, creativity \& organization: Texts, cases, and readings. Englewood Cliffs, New Jersey: Prentice Hall, 1989.

KOTTER, J. Afinal, o que fazem os líderes: a nova face do poder e da estratégia. Rio de Janeiro: Campus, 2000.

LUNDVALL, B. A. National systems of innovation: towards and theory of innovation and interactive learning. London: Printer Publishers, 1992.

. ; JOHNSON, B.; ANDERSEN, E.S.; DALUM, B. National systems of production innovation and competence building. Research Policy, v. 31, p. 213-231, 2002.

MARSHALL, A. Princípios de Economia. 2. ed. São Paulo: Nova Cultural, 1985.

MARTINELLI, A. Entrepreneurship and management. In: SMELSER, N.; AWEDBERG, R. (Eds.). The Handbook of Economic Sociology. Princeton: Princeton University Press, 1994.

MAUÁ - O Imperador e o Rei. Direção: Sérgio Rezende. Produção: Europa Filmes. Intérpretes: Paulo Betti; Malu Mader; Othon Bastos; Antonio Pitanga; Michael Byrne; Rodrigo Penna e outros. Produção executiva: Joaquim Vaz de Carvalho, Ricardo Pinto e Silva; Roberto Mader. Vídeolar, 2004. DVD (138 min), son., color., dolby digital 2.0.

MAUÁ, V. de. Exposição aos credores e ao público. São Paulo: Expressão e Cultura, 1996.

MCCLELLAND, D. C. The Achievement Society. Princeton, New Jersey: D. Van Nostrand Co., 1991.

MERRIAM, S. B. Qualitative research and case study applications in education. San Francisco: Jossey-Bass Publishers, 1998.

METCALFE, S. O empreendedor e o estilo da economia moderna. In: CASTRO, A. C. et al. (Orgs.). Brasil em desenvolvimento. Rio de Janeiro: Civilização Brasileira, 2005.

MINTZBERG, H.; AHLSTRAND, B.; LAMPEL, J. Safári de estratégia: um roteiro pela selva do planejamento estratégico. Porto Alegre: Bookman, 2000.

NONAKA, I.; TAKEUCHI, H. Criação do Conhecimento na Empresa. Rio de Janeiro: Campus, 1997.

PATTON, M. Q. Qualitative research and evaluation methods. London: Sage Publications, 2002.

POSSAS, M. L. Concorrência schumpteriana. In: KUPFER, D.; HASENCLEVER, L. (Org.). Economia Industrial: Fundamentos teóricos e práticos no Brasil. Rio de Janeiro: Campus, 2002.

RICHARDSON, R. J. e colaboradores. Pesquisa social - métodos e técnicas. 3. Ed. São Paulo: Atlas, 1999.

ROBBINS, S.P. Comportamento Organizacional. 11. ed. São Paulo: Pearson Prentice Hall, 2005.

SCARBOROUGH, H. M.; ZIMMERER, T. W. Effective small business management and entrepreneurial approach. 6. ed. Upper Saddle River, New Jersey: Prentice Hall, 2000.

SCHÖLLHAMMER, H. M.; KURILOFF, J. Entrepreneurship and small business management. New York: John Wiley \& Sons, 1979.

SCHUMPETER, J. A. Ensayos. Barcelona: Oikos-tan, 1968. 
. Teoria do Desenvolvimento Econômico. São Paulo: Nova Cultural, 1988.

SELLTIZ, Claire et al. Métodos de pesquisa nas relações sociais. São Paulo: Edusp, 1987.

SENGE, P. A quinta disciplina. São Paulo: Editora Best Seller, 1990.

SHANE, S.; VENKATARAMAN, S. The promise of entrepreneurship as a field of research. Academy of Management Review, v. 25, n. 1, jan., p. 217-226, 2000.

SOUZA, E.C.L.de. Empreendedorismo: da gênese à contemporaneidade. In: SOUZA, E. C. L. de; GUIMARÃES, T. de A. Empreendedorismo além do plano de negócios. São Paulo: Atlas 2005.

STEWART JR., W. H.; ROTH, P. L. A Meta-analysis of achievement motivation differences between entrepreneurs and managers. Journal of Small Business Management, v. 45, n. 4, p. 401-421, 2007.

TANG, J. Environmental munificence for entrepreneurs: entrepreneurial alertness and commitment. International Journal of Entrepreneurial Behavior \& Research, v. 14, n. 3, p. 128-151, 2008.

TAORMINA, R. J.; LAO, S. K. Measuring Chinese entrepreneurial motivation: personality and environmental influences. International Journal of Entrepreneurial Behavior \& Research, v. 13, n. 4, p. 200-221, 2007.

TEIXEIRA, F. L. C.; GUERRA, O. Redes de aprendizado em sistemas complexos de produção: o caso da Maxpetro. Revista de Administração de Empresas, FGV, São Paulo, v. 42, n.4, out/dez 2001.

VERBEU, I.; WENNEKERS, S.; THURIK, R. An ecletic theory of entrepreneurship: policies, institutions and culture. Amsterdam: Tinbeergen Institute, 2001.

VERSTRAETE, T. Entrepreneuriat: modélisation du phénomène. Revue de l'Entrepreneuriat, v. 1, n. 1, p. 5-24, 2001. 